\title{
201 EFFECT OF AUTOGENIC TRAINING AND MENTAL IMAGERY ON THE TRAIT ANXIETY OF THE HOCKEY PLAYERS
}

Chitra Dhiman, ${ }^{1}$ Harneet Shallu Bedi² ${ }^{1}$ Research Fellow, Department of Psychology, Netaji Subhas National Institute of Sports, Patiala, Punjab, India; ${ }^{2} J u n i o r$ Scientific Officer, Department of Psychology, Netaji Subhas National Institute of Sports, Patiala, Punjab, India

10.1136/bjsm.2010.078725.201

The present research investigation was an attempt to enhance the performance of the hockey players by regulating their trait anxiety level through implementing autogenic training and mental imagery. Pre- and post-test design was used for this purpose. Sample of the study included 31 hockey players of Netaji Subhas National Institute of Sports, Patiala. The trait anxiety test (Spielberger 1973) was used to assess trait anxiety of the participants in pre- and post-test conditions. In order to analyse pre- and post-test data test was applied. The findings revealed that the trait anxiety of the hockey players was significantly reduced, t-ratio $=3.84^{* *}, \mathrm{p}<0.01$, in post-test condition (mean $=29.55$ ) as compared to the pretest condition (mean $=36.81$ ). The concerned coaches had observed improvement in the performance of the hockey players. 